\title{
Direct Diode Laser Cladding of Inconel 625/WC Composite Coatings
}

\author{
Damian Janicki* - Małgorzata Musztyfaga-Staszuk \\ Silesian University of Technology, Faculty of Mechanical Engineering, Poland
}

Metal matrix composite coatings, composed of Inconel 625 alloy and tungsten carbide (WC), have been produced by laser cladding using a high power direct diode laser with a rectangular laser beam spot and a top-hat beam profile. The primary goal of the investigation was to understand the role of the shape of WC particles and the heat input level on the quality of the composite coating system used, especially on its erosion behaviour. The results indicated that angular WC particles are more susceptible to dissolution in the molten pool than spherical. However, the composite coatings containing angular WC particles exhibited significantly higher erosion resistance than those with spherical WC for both normal and oblique impacts. This is directly attributed to the excellent mechanical interlocking of the angular WC in the matrix. The WC/matrix interfacial decohesion has been observed in the coatings containing spherical WC at the oblique impact.

Keywords: metal matrix composite coating, Inconel 625, erosive wear, laser cladding, diode laser, tungsten carbide
Highlights
- $\quad$ A diode laser with a rectangular beam spot and the uniform distribution of laser power (top-hat beam) was used to fabricate Inconel 625-based composite coatings (CCs) with angular and spherical WC particles.
- The degree of WC dissolution depends on the heat input level but also on the shape of WC particles.
- The shape of WC particles plays a crucial role in the erosion resistance of the CCS.
- The irregularly shaped (angular) WC particles, because of better mechanical interlocking with the matrix, provides higher erosion resistance of CCs for both normal and oblique impact.
- $\quad$ The spherical WC particles are prone to the WC/matrix interfacial decohesion at oblique impact.

\section{INTRODUCTION}

In the previous decade, significant advances have been made in the fabrication of metal matrix composite coatings (MMCCs) via a laser-cladding process [1]. This process markedly reduces the high degree of dissolution of reinforcing particles (RP) that occurs during the plasma transferred arc (PTA) process [2]. Because of the precise control of the heat input and the rapid solidification associated with the laser-cladding process, the resulting MMCCs have a homogeneous distribution of the RPs and a very low degree of the RPs dissolution in the alloy matrix [3]. The high power direct diode laser (HPDDL) with uniform intensity distribution over rectangular beam spot (called a top-hat beam) is especially well suited for the fabrication of MMCCs via both ex-situ [4] and in-situ methods [5].

Alloy 625 (Inconel 625) is a nickel-based alloy that was originally developed for high-temperature turbine applications. However, because of its combination of good oxidation, corrosion resistance and moderate mechanical strength, Alloy 625 is utilized extensively as a coating material for marine environments and also for the hard-facing of tool and die steels [6]. Several studies have shown that this alloy is also a promising candidate for the alloy matrix in the MMCCs [7]. These MMCCs are a potential approach to achieve protective coatings for industrial applications requiring high resistance to both corrosion and erosion. It is well known that the MMCCs containing tungsten carbide (WC) are particularly suitable for erosive environments, due to excellent wear characteristic of this coating system [8]. In the case of the above-mentioned composite coating system, several important issues must be considered. Due to a low heat of formation, WC is prone to dissolution in the molten pool during the cladding process [9]. The dissolution of WC in the matrix alloy gives rise to the formation of secondary phases, which in turn leads to both the deterioration of wear properties of the coatings and increased sensitivity to cracking [10]. Scant data is available on the effect of WC particles shape on the nickel-based MMCCs' performance. However, the shape of WC particles in those coatings can influence their microstructure and especially erosion resistance that this study attempts to explore.

In this study, the MMCCs, composed of Inconel 625 alloy and tungsten carbide (spherical and angular in shape), have been produced by laser cladding using an HPDD laser with a rectangular laser beam spot and the uniform distribution of laser power (tophat beam). The coatings were characterized in terms 
of their structure, microhardness and erosive wear behaviour.

\section{EXPERIMENTAL PROCEDURE}

\subsection{Materials}

A commercially available Inconel 625 powder with a particle size range of $40 \mu \mathrm{m}$ to $100 \mu \mathrm{m}$ was chosen as the alloy matrix of the composite coatings. The chemical composition of this alloy is shown in Table 1. To study the effect of reinforcing particles' (RPs) morphology on the microstructure of the composite coatings and their erosion behaviour, angular and spherical cast tungsten carbide powders $\left(\mathrm{WC} / \mathrm{W}_{2} \mathrm{C}\right)$ were used. In both cases, the $\mathrm{WC} / \mathrm{W}_{2} \mathrm{C}$ particles size were in a range of $100 \mu \mathrm{m}$ to $200 \mu \mathrm{m}$ and their volume fraction in the cladding powders was $60 \%$. The size range of $\mathrm{WC} / \mathrm{W}_{2} \mathrm{C}$ particles was selected based on previous works [3]. In order to investigate the effect of the RPs addition to the cladding powder on the geometry of the single-pass clad and the microstructure of the alloy matrix, the pure Inconel 625 powder (without RPs) was also used as the coating material. A stainless steel AISI 304 plate of 10 $\mathrm{mm}$ in thickness was used as the substrate material. The chemical composition of the substrate material is also presented in Table 1. The SM was brushed with a stainless steel wire brush and cleaned with acetone prior to the cladding process.

\subsection{Laser Processing}

The laser-cladding process was carried out using an HPDD laser Rofin DL020 with a maximum output power of $2.0 \mathrm{~kW}$. The rectangular beam of $1.8 \mathrm{~mm}$ $\times 6.8 \mathrm{~mm}$ at the focal plane was focused on the top surface of the substrate. The short axis of the beam was set parallel to the traverse direction. The cladding powder was injected into the molten pool using an off-axis flat powder injection nozzle. The molten pool was protected by a shielding gas: argon at a flow rate of $10 \mathrm{l} / \mathrm{min}$. The cylindrical shielding gas nozzle with a diameter of $20 \mathrm{~mm}$ was set coaxially with the powder feeding nozzle.

To study the influence of the heat input level on the single-pass clad geometry, microstructure, and hardness, the experiments were conducted at four laser power levels, ranging from $800 \mathrm{~W}$ to $1400 \mathrm{~W}$, while traverse speed and powder feed rate were held constant at $0.2 \mathrm{~m} / \mathrm{min}$ and $0.8 \mathrm{~cm}^{3} / \mathrm{min}$, respectively. The coatings were produced by the multi-pass overlapping cladding with an overlap ratio of $30 \%$. All cladding trials were performed without preheating the substrate.

\section{RESULTS}

\subsection{Macro and Microstructure Analysis}

The cross-sectional macrographs of single-pass clads with the angular and spherical WC particles produced at a laser power of $1000 \mathrm{~W}$ (heat input of $300 \mathrm{~J} / \mathrm{mm}$ ) are presented in Fig. 1. The laser-cladding conditions and geometrical parameters of the resulting singlepass clads are summarized in Table 2. The dilution rate of the clad was estimated using the Eq. (1):

$$
U[\%]=\frac{F_{B M}}{F_{B M}+R A} \cdot 100,
$$

where $F_{B M}$ is the melted cross-sectional area of the substrate and $R A$ is the cross-sectional area of the reinforcement of the clad. The above-mentioned geometrical parameters were measured on crosssectional macrographs of single-pass clads using an optical microscope and image analyser software.

The cross-sectional SEM microstructure of the metallic Inconel 625 coating produced at the heat input (HI) of $420 \mathrm{~J} / \mathrm{mm}$ is presented in Fig. 2. Typical SEM images of the microstructure of composite coatings with the spherical and angular WC particles, produced at different heat input levels are shown in Figs. 3 and 4, respectively. For convenience, the composite coatings with angular and spherical WC particles have been labelled CCAs and CCSs, respectively. A summary of measurements of $\mathrm{WC}$ volume fractions and the matrix mean free path between the WC particles in the composite coatings is given in Table 2. The WC volume fraction and the matrix mean free path were measured using a Nikon NIS-Elements quantitative image analysis system. The measurements were conducted on cross-sections from the under surface and middle areas of the coatings, over a total area of $10 \mathrm{~mm}^{2}$ for each coating.

Table 1. Chemical compositions of the alloy matrix powder (Inconel 625) and substrate used (\% weight)

\begin{tabular}{lcccccccccc}
\hline Materials & $\mathrm{C}$ & $\mathrm{Cr}$ & $\mathrm{Mo}$ & $\mathrm{Fe}$ & $\mathrm{Mn}$ & $\mathrm{Nb}$ & $\mathrm{Al}$ & $\mathrm{Si}$ & $\mathrm{Ti}$ & $\mathrm{Ni}$ \\
\hline Inconel 625 powder & 0.02 & 19.6 & 5.8 & 1.6 & - & 3.9 & 0.1 & 0.4 & 0.15 & Balance \\
\hline AISI 304 plate & 0.08 & 18.9 & - & Balance & 2.0 & - & - & 1.0 & - & 10.0 \\
\hline
\end{tabular}


Table 2. Parameters of HPDDL cladding process and measured geometrical parameters of the single-pass clads and microstructural parameters of the composite coatings

\begin{tabular}{|c|c|c|c|c|c|c|c|}
\hline Clad/coating no. & WC shape & $\begin{array}{l}\text { Laser power } \\
\text { [W] }\end{array}$ & $\begin{array}{c}\text { Heat input* } \\
{[\mathrm{J} / \mathrm{mm}]}\end{array}$ & $\begin{array}{c}\text { Dilution } \\
{[\%]}\end{array}$ & $\begin{array}{l}R A^{* *} \\
{\left[\mathrm{~mm}^{2}\right]}\end{array}$ & $\begin{array}{l}\text { Matrix mean free } \\
\text { path }[\mu \mathrm{m}]\end{array}$ & $\begin{array}{c}\text { Volume fraction } \\
\text { of WC [\%] }\end{array}$ \\
\hline $\mathrm{A} 1$ & \multirow{4}{*}{ angular } & 800 & 240 & 28 & 2.3 & $46 \pm 25$ & 54 \\
\hline $\mathrm{A} 2$ & & 1000 & 300 & 35 & 2.7 & $48 \pm 25$ & 52 \\
\hline A3 & & 1200 & 360 & 40 & 3.1 & $52 \pm 30$ & 49 \\
\hline A4 & & 1400 & 420 & 42 & 3.4 & $62 \pm 35$ & 45 \\
\hline S1 & \multirow{4}{*}{ spherical } & 800 & 240 & 31 & 2.1 & $37 \pm 15$ & 58 \\
\hline S2 & & 1000 & 300 & 34 & 2.7 & $39 \pm 15$ & 56 \\
\hline S3 & & 1200 & 360 & 37 & 3.0 & $45 \pm 20$ & 54 \\
\hline S4 & & 1400 & 420 & 41 & 3.3 & $49 \pm 25$ & 50 \\
\hline $\mathrm{M} 1^{\star \star \star}$ & & 800 & 240 & 6 & 3.0 & - & - \\
\hline M2 & & 1000 & 300 & 7 & 3.8 & - & - \\
\hline $\mathrm{M} 3$ & & 1200 & 360 & 14 & 4.5 & - & - \\
\hline M4 & & 1400 & 420 & 18 & 4.6 & - & - \\
\hline
\end{tabular}

Remarks: * defined as the laser power divided by the traverse speed, ** the cross-sectional area of reinforcement of the single-pass clad, $* * *$ metallic Inconel 625 clad

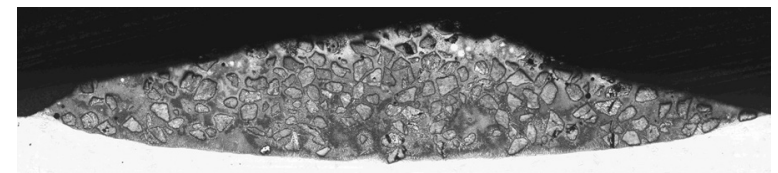

a) $500 \mu \mathrm{m}$

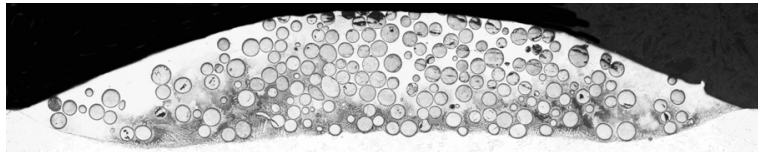

b) $500 \mu \mathrm{m}$

Fig. 1. Macrographs of single-pass clads produced at the HI of $300 \mathrm{~J} / \mathrm{mm}$ using powder with a) spherical WC (clad no. S2), and b) angular WC (clad no. A2)

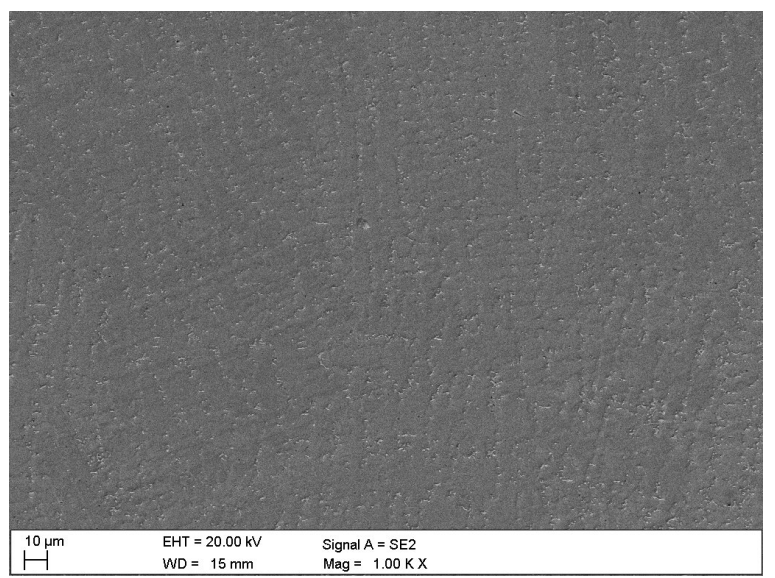

Fig. 2. SEM micrograph taken from the mid-section of metallic Inconel 625 coating produced at the $\mathrm{HI}$ of $420 \mathrm{~J} / \mathrm{mm}$ (coating no. M4)

Typical dimensions of the composite singlepass clads are a width of approx. $5.5 \mathrm{~mm}$ and height in the range of $0.8 \mathrm{~mm}$ to $0.9 \mathrm{~mm}$. The thickness of composite coatings fabricated by multi-pass overlapping with an overlap ratio of $30 \%$ was about $1.5 \mathrm{~mm}$, in the whole range of the heat input.
The X-ray diffraction patterns of the metallic Inconel 625 coating and composite coatings produced at the heat input of $300 \mathrm{~J} / \mathrm{mm}$ are presented in Fig. 5 . The X-ray diffraction measurements were performed using a PANalytical X'Pert PRO MPD X-ray diffractometer equipped with a Co- $\mathrm{K}_{\alpha}(\lambda=0.179 \mathrm{~nm})$ source and an $\mathrm{X}^{\prime}$ Celerator detector. The $\mathrm{X}$-ray tube was operated at $40 \mathrm{kV}$ and $30 \mathrm{~mA}$. XRD analysis of the metallic Inconel 625 coating detected only the presence of the FCC $\gamma$-Ni phase. In turn, the composite coatings contain the FCC $\gamma$-Ni phase, WC, $\mathrm{W}_{2} \mathrm{C}$ and also a relatively significant fraction of complex carbide $\mathrm{Fe}_{3} \mathrm{~W}_{3} \mathrm{C}$. Moreover, XRD analysis indicated that the fraction of $\mathrm{Fe}_{3} \mathrm{~W}_{3} \mathrm{C}$ phase in the CCAs and CCSs is almost similar.

\subsection{Hardness Testing}

Microhardness testing was conducted using Wilson Wolpert 401 MVD Vickers hardness tester. To determine the hardness of the matrix and WC particles the load of $200 \mathrm{~g}$ for a dwell time of $10 \mathrm{~s}$ was used. The average hardness of the secondary phases was measured using $10 \mathrm{~g}$ load for a dwell time of $5 \mathrm{~s}$. The 

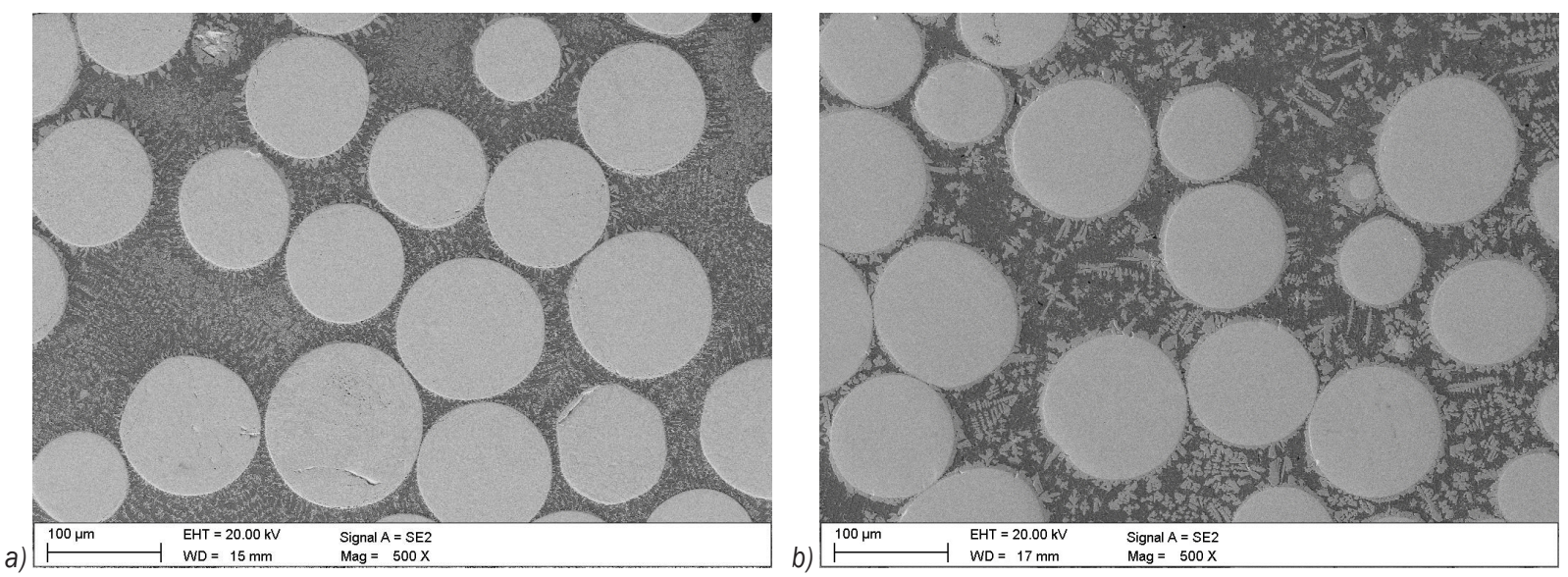

Fig. 3. SEM micrographs taken from the mid-section of the CCSs produced at the HI of a) $240 \mathrm{~J} / \mathrm{mm}$ (coating no. S1);

b) $420 \mathrm{~J} / \mathrm{mm}$ (coating no. S4)
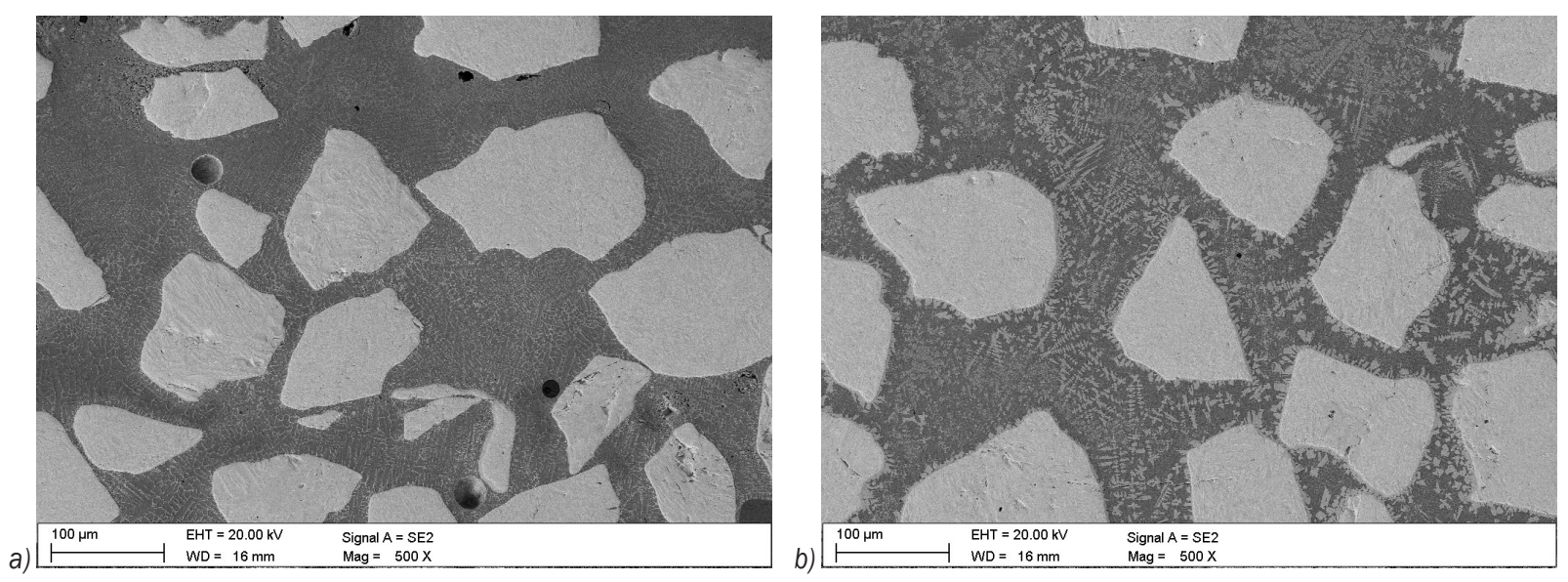

Fig. 4. SEM micrographs taken from the mid-section of the CCAs produced at the HI of a) $240 \mathrm{~J} / \mathrm{mm}$ (coating no. A1);

b) $420 \mathrm{~J} / \mathrm{mm}$ (coating no. A4)

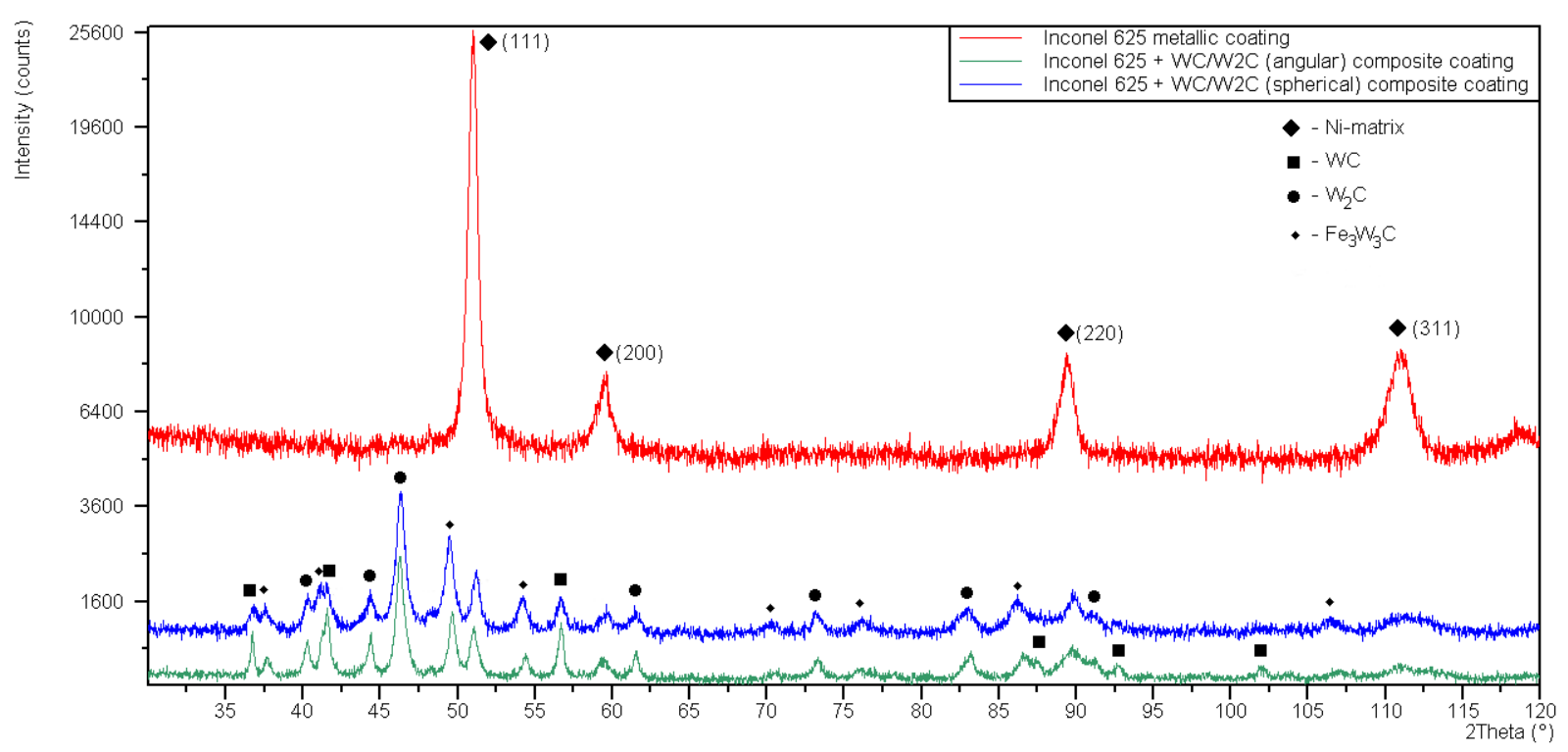

Fig. 5. XRD patterns of the metallic and composite coatings produced at the heat input of $300 \mathrm{~J} / \mathrm{mm}$ 
metallic Inconel 625 coatings exhibited a constant hardness of approx. $230 \mathrm{HV}$, in the whole range of HI. In the case of composite coatings, the average hardness of matrix increased from $300 \mathrm{HV}$ at the lowest $\mathrm{HI}$ to $500 \mathrm{HV}$ at the highest HI. The hardness of both types of WC particles was about $2100 \mathrm{HV}$. The average microhardness of the secondary dendritic and blocky $\mathrm{Fe}_{3} \mathrm{~W}_{3} \mathrm{C}$ phases was found to be $1000 \mathrm{HV} \pm 100 \mathrm{HV}$.

\subsection{Erosion Testing}

Results of erosion tests of the metallic Inconel 625 coating (MC), CCAs and CCSs, produced at $\mathrm{HI}$ of $300 \mathrm{~J} / \mathrm{mm}$ are given in Table 3 .

Table 3. Results of erosion tests of the MC and CCs

\begin{tabular}{cccc}
\hline $\begin{array}{c}\text { Coating } \\
\text { label }\end{array}$ & $\begin{array}{c}\text { Impact } \\
\text { angle }\left[{ }^{0}\right]\end{array}$ & $\begin{array}{c}\text { Average erosion } \\
\text { rate* }^{*}[\mathrm{mg} / \mathrm{min}]\end{array}$ & $\begin{array}{c}\text { Average erosion value**} \\
{\left[0.001 \mathrm{~mm}^{3} / \mathrm{g}\right]}\end{array}$ \\
\hline \multirow{2}{*}{$\mathrm{MC}$} & 90 & 0.31 & 18.36 \\
\cline { 2 - 4 } & 30 & 0.60 & 35.54 \\
\hline \multirow{2}{*}{ CCA } & 90 & 0.61 & 24.80 \\
\cline { 2 - 4 } & 30 & 0.21 & 8.54 \\
\hline \multirow{2}{*}{ CCS } & 90 & 1.07 & 43,50 \\
\cline { 2 - 4 } & 30 & 0.34 & 13.82 \\
\hline
\end{tabular}

Remarks: ${ }^{*}$ calculated as the mass loss of the specimen divided by total test time; ${ }^{* *}$ calculated by dividing the erosion rate by the erodent flow rate and then dividing by the coating density.

The HI level used provided non-porous composite coatings (CCs) with low dissolution level of WC particles. The solid-particle erosion testing system used in this study was designed in accordance with standard ASTM G 76-95. Angular alumina powder $\left(\mathrm{Al}_{2} \mathrm{O}_{3}\right)$ with an average particle size of $50 \mu \mathrm{m}$ was used as erodent material. The erodent particles were accelerated in a stream of compressed air along a cylindrical tungsten carbide nozzle having an internal diameter of $1.5 \mathrm{~mm}$ and a length of $50 \mathrm{~mm}$. The standoff distance, from the end of the nozzle to the surface of the specimen, was $10 \mathrm{~mm}$. All tests were performed at an erodent impingement velocity of $70 \mathrm{~m} / \mathrm{s} \pm 2 \mathrm{~m} / \mathrm{s}$. The feed rate of the erodent and the test period were $2.0 \mathrm{~g} / \mathrm{min} \pm 0.25 \mathrm{~g} / \mathrm{min}$ and $10 \mathrm{~min}$, respectively. The impingement angles selected were $30^{\circ}$ and $90^{\circ}$. Prior to erosion testing, the surface of the coatings was ground to a smooth finish using a 400 grit diamond wheel. The weight loss of the erosion specimens was determined by weighting the specimens before and after the erosion tests to the nearest $0.01 \mathrm{mg}$. The specimens were ultrasonically cleaned in acetone before weighing. Following ASTM Standard G76 [11], erosion values were calculated as the volume loss of erosion specimen per mass of erodent particles used over each test period. The wear surfaces were examined using scanning electron microscope (Figs. 10 and 11).

\section{DISCUSSION}

\subsection{Macro and Microstructure Analysis}

The dilution level of the composite single-pass clads was even 5 times higher than that of the metallic produced at the same HI levels (Table 2). This is associated with the higher absorption coefficient of tungsten carbide compared to the alloy matrix absorption coefficient. Furthermore, the dilution level is strongly affected by the laser power, which is connected to the intensity of the convection movement in the molten pool driven by surface tension. The higher laser power gives rise to more intensive fluid flow in the molten pool, and as a result higher dilution. In the investigated range of cladding parameters, the dilution level of the metallic and composite singlepass clads can be controlled from $6 \%$ to $18 \%$ and from $28 \%$ to $42 \%$, respectively. Moreover, with increasing laser power level, the cross-sectional area of reinforcement of the single-pass clads increases, which in turn results from a higher powder capture efficiency occurring at the higher laser power, during the laser cladding with an off-axis powder injection system. Because of a short interaction time between the laser beam and the powder stream, during this cladding process, a melting of the powder particles occurs only when they enter the molten pool. In this case, the capture efficiency depends directly on the size of the molten pool. The higher laser power leads to the larger molten pool area and the larger amount of captured powder and, in consequence, the larger reinforcement area of the clad.

In comparing the reinforcement areas of the metallic and composite single-pass clads (Table 2 ), it can be seen that the capture efficiency of the metallic powder is approx. $25 \%$ higher than that of the composite powder. It is consistent with the abovementioned mechanism of powder capture. Generally, the WC particles undergo only partial melting in the molten pool; thus, their relatively high volume fraction in the cladding powder significantly limits the volume of the molten matrix alloy which is responsible for powder capturing. The shape of WC particles in the cladding powder has no significant effect on the geometry of single-pass clads and the powder capture efficiency (Fig. 1).

In general, the microstructure of the metallic Inconel 625 coatings consists of austenite grains 
and interdendritic areas enrich in $\mathrm{Nb}$ and Mo (Fig. 2 ). The morphology of austenite grains varies from the fusion boundary to the coating surface, due to changes in the local solidification conditions. The temperature gradient is the highest at the fusion boundary promoting columnar dendritic growth in a direction opposite to the direction of heat transfer. Towards the coating surface, the temperature gradient becomes lower, which (in combination with a higher solidification rate) results in significant undercooling leading to the formation of equiaxed dendrites. Based on energy-dispersive X-ray spectroscopy (EDS) analysis, the mean concentration of $\mathrm{Fe}$ in the metallic Inconel 625 coating produced at the highest HI (420 $\mathrm{J} / \mathrm{mm}$ ) was estimated to be $16.2 \%$. This value is in good agreement with the geometrical measurement of the dilution, listed in Table 2. The metallic coatings produced throughout the range of HI levels were free of porosity, microvoids, and microcracks.

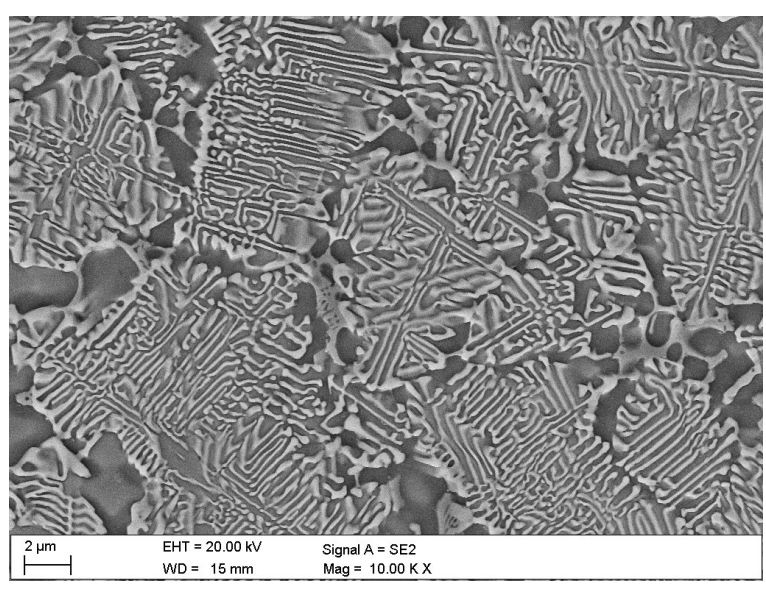

Fig. 6. SEM micrograph showing the fishbone-like W-rich phases in the interdendritic areas in the composite coatings (coating no. A1)

Both types of the RPs enable producing the composite coatings with a uniform distribution of the RPs throughout the alloy matrix (Figs. 3 and 4). Moreover, the top-hat beam profile of the HPDD laser prevents the RPs from dissolving in overlap zones between consecutive passes. A transition region (interphase) between the RP and the matrix is continuous and free of defects throughout the range of the HI. Both the CCAs and CCSs produced at the lowest $\mathrm{HI}(240 \mathrm{~J} / \mathrm{mm})$ exhibited a negligible dissolution of the RPs leading to the insignificant enrichment of the alloy matrix in the tungsten. In this case, the alloy matrix showed the dendritic growth of austenite grains and fishbone-like (herringbonelike) W-rich phases located in the interdendritic areas
(Fig. 6). The dendrite cores were enriched in $\mathrm{W}$ and Fe up to $2 \%$ and $36 \%$, respectively. The $\mathrm{W}$ and Fe content in the interdendritic areas was approx. $39 \%$ and $28 \%$, respectively. The interdendritic areas also contain the $\mathrm{Nb}$-rich eutectic-like structures, shown in Fig. 7. Furthermore, in comparison to the metallic coating produced at the same HI level, the austenite grain size was refined. EDS line-scan analysis collected in the transition region, presented in Fig. 8, revealed a relatively shape change in the concentration of $\mathrm{W}, \mathrm{Ni}, \mathrm{Fe}$ and $\mathrm{Cr}$. This indicates the low decomposition of outer layers of the WC particles in the molten pool, at that HI level. Moreover, the minor porosity was observed in those composite coatings.

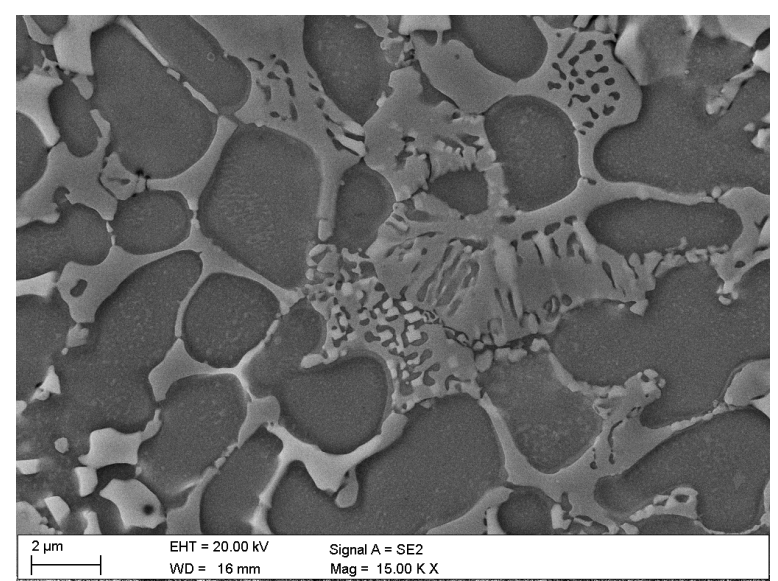

Fig. 7. SEM micrograph showing the Nb-rich eutectic-like structures in the interdendritic areas in the composite coating (coating no. S1)

Generally, the increase of the HI level gives rise to an increase of the RPs dissolution, which in turn leads to the formation of dendritic and blocky W-rich phases, as the results of the considerable enrichment of the alloy matrix in tungsten. Quantitative analysis of micrographs of the CCAs and CCSs produced at the $\mathrm{HI}$ of $240 \mathrm{~J} / \mathrm{mm}$ indicates that the RPs occupy about 54 vol.\% and 58 vol.\%, respectively. In the case of the CCAs and CCSs produced at the HI of $420 \mathrm{~J} / \mathrm{mm}$, the volume fraction of the RPs was $45 \%$ and $50 \%$, respectively. This implies that about 25 vol. $\%$ and 17 vol.\% of the RPs have undergone dissolution in the above-mentioned composite coatings, respectively. Furthermore, it follows that the angular RPs are more susceptible to dissolution in the molten pool than spherical ones are. It can be attributed to the sharp ages of the angular RP that are easily melted in the molten pool, which is further confirmed by rounded RPs at the high HI levels (Fig. 4b). Moreover, the spherical 


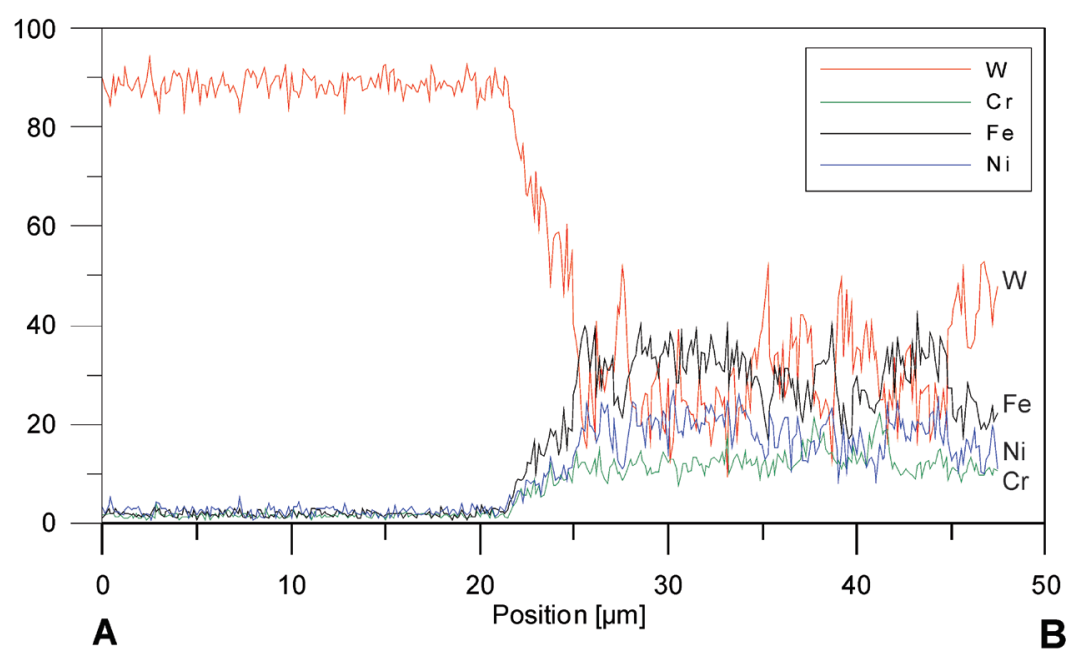

Fig. 8. EDS line-scan analysis across the transition region in the CCS produced at the $\mathrm{HI}$ of $240 \mathrm{~J} / \mathrm{mm}$; profile taken along the line marked in Fig. 9a

shape minimizes the contact area of molten metal and the RP, reducing, to the same extent, the amount of heat introduced to the RP in the molten pool.

Additionally, it is noteworthy that the morphology of the transition region between the RP and the matrix is affected by the HI level. At the lowest HI the transition region exhibits lamellar WC phases directly adjacent to the surface of RPs (Fig. 9a). The presence of these phases results from both a very slight decomposition of the outer layers of the RPs in the molten pool and the different thermodynamic stability of $\mathrm{WC}$ and $\mathrm{W}_{2} \mathrm{C}$ carbides. The cast tungsten carbide used was a eutectic mixture of $\mathrm{W}_{2} \mathrm{C}$ and $\mathrm{WC}$. The $\mathrm{W}_{2} \mathrm{C}$ carbide, due to the lower thermal stability at high temperature in comparison to the WC carbide, undergoes dissolution in the molten pool while the WC remains intact. The increase in the HI leads initially to the formation of thin layers of $\mathrm{W}_{2} \mathrm{C}$ around the RPs. Further increase of the HI results in the formation of dendritic and blocky W-rich phases in the transition region (Fig. 9b). The presence of these phases provides a gradient distribution of all elements across the transition region but also leads to the widening of the transition region (up to $12 \mu \mathrm{m}$ ). In the case of the highest HI $(420 \mathrm{~J} / \mathrm{mm})$, thus at the highest dissolution level of the RPs, the above-mentioned secondary W-rich phases are uniformly distributed throughout the spaces between RPs. The EDS spot analysis of those phases revealed a high $\mathrm{W}$ and Fe content, suggesting that they are complex carbides $\left(\mathrm{M}_{6} \mathrm{C}\right) \mathrm{Fe}_{3} \mathrm{~W}_{3} \mathrm{C}$. X-ray diffraction results confirmed the presence of $\mathrm{Fe}_{3} \mathrm{~W}_{3} \mathrm{C}$ in both the CCA and CCS
(Fig. 5). In addition, XRD analysis revealed the similar volume fraction of the Fe3W3C phase in both types of composite coatings. A relatively significant volume fraction of those complex carbide phases, at the highest HI, (up to about $14 \%$ ) is a result of both high dissolution of RPs and the dilution level. In the composite coatings produced at the highest HI level, the fishbone structure was observed mainly in the region near the fusion boundary. These observations indicate that the formation of the fishbone-like phases can be promoted by the high cooling rates and also high Fe concentration.

The matrix mean free path (MFP) between the RPs is affected by both the HI and the shape of the RPs. In the investigated range of the HI, as denoted in Table 2, an increase in the HI increased the MFP from $46 \mu \mathrm{m} \pm 25 \mu \mathrm{m}$ to $62 \mu \mathrm{m} \pm 35 \mu \mathrm{m}$, and from $37 \mu \mathrm{m} \pm 15 \mu \mathrm{m}$ to $49 \mu \mathrm{m} \pm 25 \mu \mathrm{m}$ in the CCA and CCS, respectively. Differences in the MFP for those coatings can be explained by a different degree of the RPs dissolution but also by the fact that the spherical particles have a better packing ability.

a)
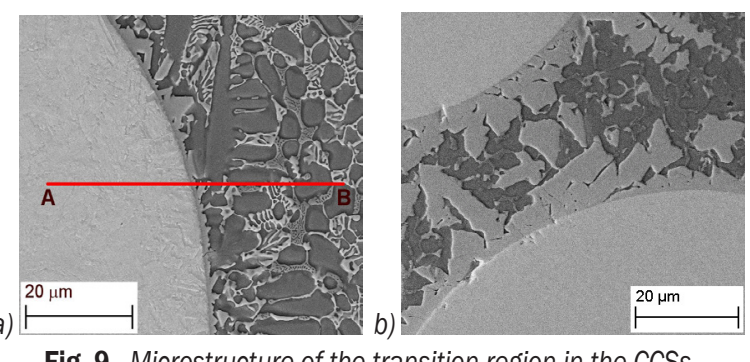

Fig. 9. Microstructure of the transition region in the CCSs produced at the $\mathrm{HI}$ of a) $240 \mathrm{~J} / \mathrm{mm}$; and b) $420 \mathrm{~J} / \mathrm{mm}$ 
All composite coatings contained a crack network induced due to a lack of preheating the substrate. The cracks propagated through the WC particles mainly perpendicular to the fusion boundary and did not affect the integrity of the metallurgical bonding between the coating and the substrate. The presence of $\mathrm{Fe}_{3} \mathrm{~W}_{3} \mathrm{C}$ phases enhances the coatings' tendency for cracking.

\subsection{Microhardness Analysis}

Microhardness measurements indicate a general trend towards increasing hardness of the composite coatings with increasing $\mathrm{HI}$ levels. This is in qualitative agreement with the microstructural characteristics described in the previous section. Namely, the increase in the HI level leads to both the reduction of the WC volume fraction and the higher mean free path between the WC particles. However, simultaneously the dissolution of $\mathrm{WC}$ results in the formation of W-rich secondary phases in the matrix. The average microhardness of the dendritic and blocky $\mathrm{Fe}_{3} \mathrm{~W}_{3} \mathrm{C}$ phases was found to be $1000 \mathrm{HV} \pm 100 \mathrm{HV}$. Their uniform distribution makes a significant contribution to the matrix hardness of the composite coatings.

\subsection{Erosion Behaviour}

It was found that erosion the values for both types of composite coatings at an erodent impact angle of $90^{\circ}$ were about three (3) times higher than those at $30^{\circ}$. Whereas in the case of the metallic Inconel 625 coating, the relation between the erosion values and erodent angles was inverse: the erosion values at an impact angle of $30^{\circ}$ was $100 \%$ higher than those at $90^{\circ}$. Additionally, the composite coatings at the impact angle of $30^{\circ}$ exhibited even four (4) times higher erosion resistance when compared with that of the metallic coating. In turn, the metallic coating possessed a slightly higher erosion resistance for the $90^{\circ}$ impact angle than the composite coatings did. These relationships are attributed to differences in the wear behaviour of the metallic and composite materials for selected erodent impact angles. The erosive wear behaviour of the metallic Inconel 625 coating is typical for ductile materials and has already been well described in the literature [12]. In the case of composite materials, the mechanism of the erosion process is much more complicated because of their complex microstructure. Generally, in this case, the erosion damage is a combination of the brittle and ductile manner of the material loss. That is, material is removed by both chipping and cracking of the RPs and through extrusion and scratching of the ductile matrix alloy. Typical SEM images showing the erosion damage within the wear crater of the CCS and CCA are shown in Figs. 10 and 11, respectively. The erosion degradation mechanism within the wear crater appears quite similar for both types of CCs. However, as denoted in Table 3, there is a significant difference between the erosion values recorded for the CCA and CCS, particularly in the impact angle of $90^{\circ}$. Taking into account the similar hardness of the matrix alloy in these coatings and, in particular, the fact that the CCSs exhibit the lower matrix mean free path (MFP), it can be considered that the above-mentioned difference in erosion resistance of the composite coatings is associated directly with the shape of the RPs. This is consistent with SEM examination of the wear surfaces, which revealed the $\mathrm{RP} /$ matrix interfacial decohesion in the CCSs eroded at the impact angle of $30^{\circ}$ (Fig. 10b). This manner of RP removal involves the nucleation of a crack and its propagation along the interface between the RP and matrix alloy. It is interesting to note that, due to the smooth $\mathrm{RP} /$ matrix interface in the CCSs, the fracture propagates tangentially around the spherical $\mathrm{RP}$, which also indicates a low interfacial bond strength. The EDS spot analysis of the fracture surface revealed high $\mathrm{W}$ and $\mathrm{Fe}$ content, suggesting that the crack propagation may occur between the RP and, precipitated on its surface, secondary phases. Such a mechanism of the RP removal was not observed in the coatings with the angular RPs. The irregularly shaped RP provides mechanical interlocking with the matrix alloy, significantly improving the RP/matrix interfacial strength.

In the case of the erodent impact angle of $90^{\circ}$, it was observed that the smooth spherical shape of RPs facilitates the removal of the matrix alloy, which consequently leads to cracking and chipping RPs into relatively large pieces. More precisely, the erodent particle impacting the RP, due to the smooth and convex $\mathrm{RP} /$ matrix interface, moves tangentially to the surface of RP, scratching it and simultaneously ploughing and cutting the matrix material in the direct vicinity of the RP. The resultant loss of matrix material and further impacts of erodent particles cause cracking of RPs and its dislodgement. The cracks propagate mainly parallel to the eroded surface resulting in the removal of relatively large pieces of the RP.

In contrast, the angular RPs are more effective in protecting the matrix alloy against ploughing and cutting action. In this case, the kinetic energy of erodent particles is dissipated into the work of the fracture of the RPs and also into the plastic 

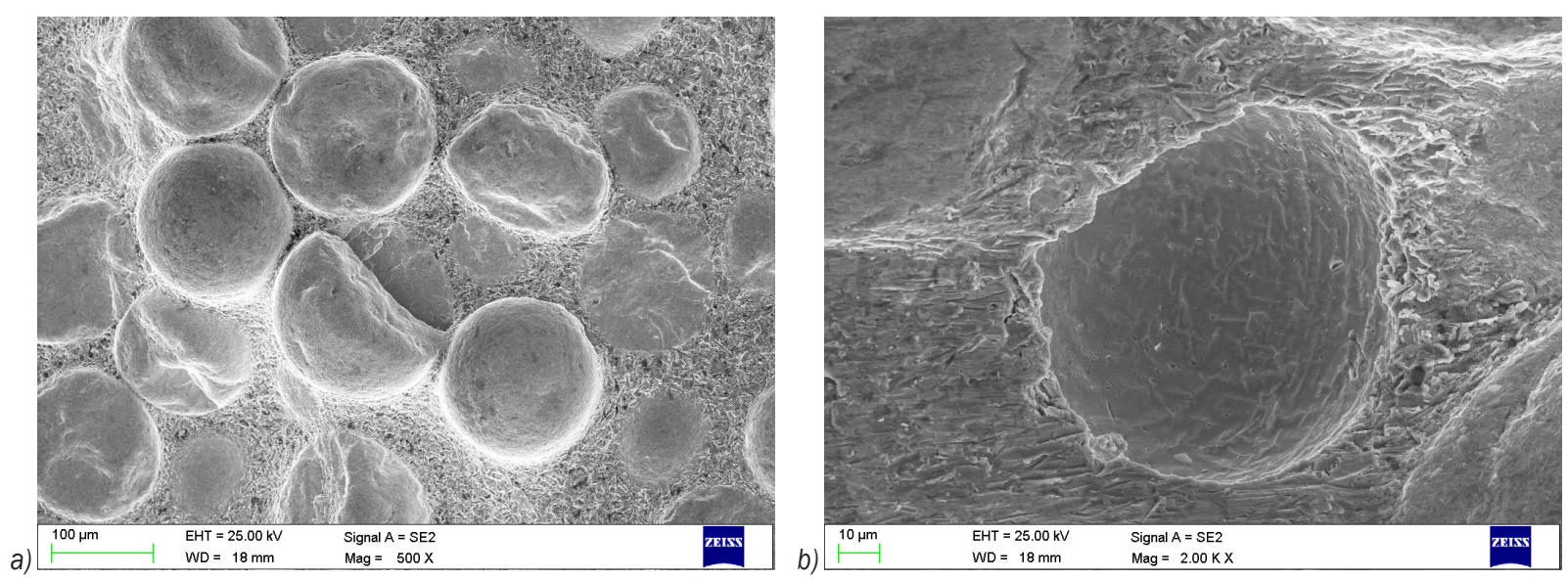

Fig. 10. SEM image of worn surfaces of the CCSs at impact angle of a) $90^{\circ}$, and b) $30^{\circ}$
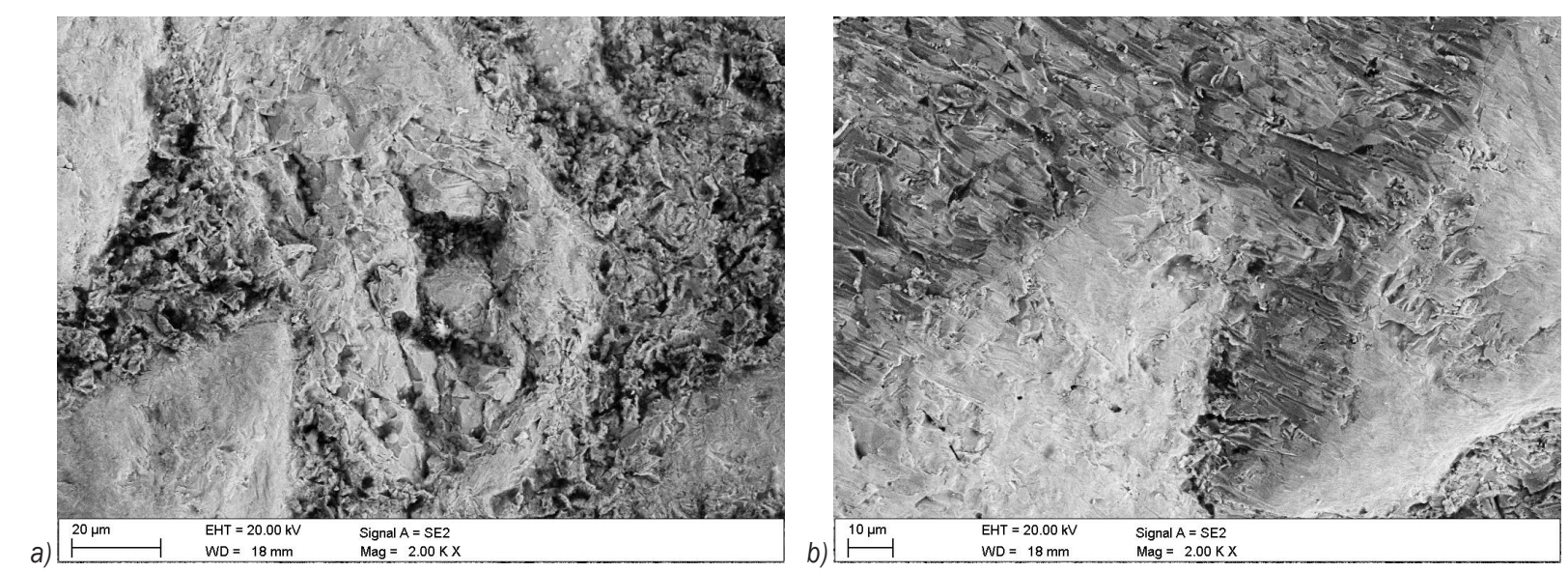

Fig. 11. SEM image of worn surfaces of the CCAs at impact angle of a) $90^{\circ}$, and b) $30^{\circ}$

deformation of the matrix. However, as can be seen in Fig. 11a, the angular RP, because of the mechanical interlocking with the matrix and neighbouring RPs, can contribute to the erosion resistance of the coating, even after crack formation. The alloy matrix is removed mainly by the detachment of plastically deformed lips, extruded to the sides of the crater by particle impact. Such erosion behaviour essentially reduces the erosion value.

\section{CONCLUSIONS}

The HPDD laser-cladded Inconel 625-based composite coatings with both angular and spherical WC reinforcing particles exhibited uniform distributions of WC throughout the matrix and defectfree transition regions between the WC particles and the matrix. With increasing HI, the dissolution of WC increases leading to the formation of secondary W-rich phases in the matrix and especially in the transition regions. The angular WC particles are more susceptible to dissolution in the molten pool than spherical ones are. The top-hat beam profile of the laser used enables to produce composite coatings at very low $\mathrm{HI}$ level, leading to a negligible dissolution of WC. At the lowest $\mathrm{HI}$ of $240 \mathrm{~J} / \mathrm{mm}$, the WC dissolution level was found to be approx. $3 \mathrm{vol} \%$ and $10 \mathrm{vol} \%$, in the coatings with spherical and angular $\mathrm{WC}$, respectively. The coatings with angular WC showed the higher matrix mean free path. However, despite the above-mentioned structural characteristic, the coatings with angular WC exhibited higher erosion resistance than those with spherical WC for both normal and oblique impacts. At an impact angle of $90^{\circ}$, erosion values of the coatings with spherical WC were almost 2 times higher than those containing angular WC. This is directly attributed to the excellent mechanical interlocking of irregular WC particles with the matrix and neighbouring WC particles. Whereas in the case of spherical WC, a very smooth interface 
with the matrix considerably facilitates a removal of the matrix at normal impact. Moreover, the spherical $\mathrm{WC}$ particles are prone to the $\mathrm{WC} /$ matrix interfacial decohesion at oblique impact.

\section{ACKNOWLEDGEMENTS}

Publication of this article was funded by a statutory grant of the Faculty of Mechanical Engineering, Silesian University of Technology.

\section{REFERENCES}

[1] Nurminen, J., Näkki, J., Vuoristo, P. (2009). Microstructure and properties of hard and wear resistant MMC coatings deposited by laser cladding. International Journal of Refractory Materials and Hard Materials, vol. 27, no. 2, p. 472-478, D0l:10.1016/j. ijrmhm.2008.10.008.

[2] Liyanage, T., Fisher, G., Gerlich, A.P. (2012). Microstructures and abrasive wear performance of PTAW deposited Ni-WC overlays using different Ni-alloy chemistries. Wear, vol. 274275, p. 345-354, D0l:10.1016/j.wear.2011.10.001.

[3] Janicki, D. (2012). High power diode laser cladding of wear resistant metal matrix composite coatings. Solid State Phenomena, vol. 199, p.587-594, Dol:10.4028/www. scientific.net/SSP.199.587.

[4] Tański T. (2014). Determining of laser surface treatment parametres used for light metal alloying with ceramic powders. Materials Science \& Engineering Technology, vol. 45, no. 5, p. 333-343, D0I:10.1002/mawe.201400232.
[5] Lisiecki, A. (2015). Titanium matrix composite Ti/TiN produced by diode laser gas nitriding. Metals, vol. 5, no. 1, p. 54-69, DOl:10.3390/met5010054.

[6] Cieslak, M.J., Headley, T.J., Roming, A.D., Kollie T., (1988). A melting and solidification study of Alloy 625. Metallurgical Transactions A, vol. 19, no. 9, p. 2319-2331, D0l:10.1007/ BF02645056.

[7] Jiang, D., Hong, C., Zhong, M., Alkhayat, M., Weisheit, A., Gasser, A., Zhang, H. Kelbassa, I., Poprawe, R. (2014). Fabrication of nano-TiCp reinforced Inconel 625 composite coatings by partial dissolution of micro-TiCp through laser cladding energy input control. Surface and Coatings Technology, vol. 249, p. 125-131, D0I:10.1016/j.surfcoat.2014.03.057.

[8] St-Georges, L. (2007). Development and characterization of composite Ni-Cr+WC laser cladding. Wear, vol. 263, no. 1-6, p. 562-566, D0l:10.1016/j.wear.2007.02.023.

[9] Klimpel, A., Dobrzański, L.A., Lisiecki, A., Janicki, D. (2005). The study of properties of Ni-WC wires surface deposits. Journal of Material Processing Technology, vol. 164-165, p. 1046-1055, D0I:10.1016/j.jmatprotec.2005.02.195.

[10] Zhou, S., Huang, Y., Zeng, X., Hu, Q. (2008). Microstructure characteristics of Ni-based WC composite coatings by laser induction hybrid rapid cladding. Materials Science and Engineering: A, vol. 480, no. 1-2, p. 564-572, D0l:10.1016/J. msea.2007.07.058.

[11] ASTM G76-13 (2013). Standard Test Method for Conducting Erosion Tests by Solid Particle Impingement Using Gas Jets. ASTM International, West Conshohocken, Dol:10.1520/ G0076.

[12] Levin, B.F., Vecchio, K.S., DuPont, J.N., Marder, A.R. (1999). Modeling solid-particle erosion of ductile alloys. Metallurgical and Materials Transactions A, vol. 30, no. 7, p. 1763-1774, DOI:10.1007/s11661-999-0175-9. 